\title{
Идентитет в интеракции
}

\author{
НАВА-ВАНДА ШАХВЕРДОВА \\ Debreceni Egyetem BTK Szlavisztikai Intézet, H-4032 Debrecen, Egyetem tér 1. \\ SAHVERDOVA Nava-Vanda, Institute of Slavic Studies, University of Debrecen \\ E-mail: sahverdova@gmail.com
}

(Received: 22 January 2018; accepted: 24 March 2018)

\begin{abstract}
The analysis focuses on two possible approaches to the phenomenon of identity. Identity emerges, it is maintained and changes in everyday talk-in-interaction in the process of communicative action interpretations achieved by speakers and their reactions. Consequently, identity can be observed in the individual narratives and in the structure of conversation. In the paper, the author observes the emergence of identity in the texts of qualitative semi-structured focus group interview (in the Russian language). The text analysis is based on the theoretical and methodological background of conversation analysis and narrative analysis.

Keywords: identity, narrative, talk-in-interaction, institutional talk, conversation analysis, narrative analysis
\end{abstract}

\section{о. Введение}

Цель настоящей статьи - демонстрация процесса зарождения идентитета в процессе речевой деятельности. Идентитет конструируется участниками дискурса в процессе интеракции посредством отожествления себя с определенным набором признаков - идентитетом, и стремлением участников интеракции поддерживать идентитет, как свой, так и собеседника. Это выражается в организации интеракции - как содержания, так и структуры интеракции. Описывая этот динамичный процесс (речь в интеракции), можно проследить создание и поддерживание феномена идентитета. Существует множество подходов к анализу речи, теоретической и методологической рамками исследования выбраны конверсационный анализ и нарративный анализ потому, что при помощи обоих легко проследить процесс конструирования, нарративный анализ кроме формального и в содержательном плане, а конверсационный анализ в раскрытии структуры интеракции. ${ }^{1}$

\section{1. Идентитет в интеракции}

Идентитет - динамичное явление, создающееся, поддерживающееся и меняющееся в процессе интеракции. Таким образом, для того, чтобы проследить это явление, мы должны наблюдать речь (BAMBERG 2011).

\footnotetext{
${ }^{1}$ Некоторые положения, изложенные в этой статье, публиковались ранее (ШАХВЕРдОВА 2012, ШАХВЕРДОВА 2016), здесь они дополнены, переосмыслены.
} 
Идентитет может быть дифференцирован как набор неких признаков, определяющих индивида. Признаки могут значительно различаться по своим качествам, поэтому трудно говорить об этом феномене (ШАХВЕРдовА 2012: 55, JENKINS 2004: 42). Набор признаков нестатичен, динамичен, способен изменяться, некоторые признаки могут быть более-менее устойчивыми, другие более диффузными. В дальнейшем описывается подход различных авторов, стремившихся обрисовать, что значит для индивида обладать идентитетом.

$\mathrm{X}$. Спенсер-Оутли, сравнивая феномены лица и идентитета, определяет последний как концепт о себе - многогранное явление, которое включает представления о чьих-то признаках (персональных, социальных, психологических и т. д.), состоит из множества аспектов «я»; действует как схема, контролирующая информацию, релевантную «я»; представляет собой внутреннее явление, индивидуальное, более общее, чем лицо; может включать и негативные оценки. Оба явления относятся к понятию само-имиджа (self-image) индивидуального, реляционного и коллективного (SPENCER-OATLEY 2007).

Ч. Антаки и С. Видикомб определяют основные характеристики, которыми обладает идентитет: для индивида обладать идентитетом - это значит быть зачисленным в какую-то категорию с ассоциированным набором признаков; это зачисление индексично и связано с обстановкой. Связь с актуальной ситуацией и индексичность определяет релевантность идентитета в текущей интеракции. Сила действия обладания идентитетом состоит в его воздействии на интеракцию. Все это обозримо в использовании структуры конверсации (ANTAKI-WIDDICOMBE 1998: 1-7).

Р. Дженкинс обращает внимание на три аспекта деятельности, определяющие повседневную деятельность индивида: индивидуальный устав мира как сконструированное воплощение внутреннего мира индивидов, как интерактивного порядка организации, созданной в процессе интерперсональных отношений, а также как порядка организации социальных институтов. Это мир привычного порядка действий в определенных ситуациях. Перечисленные установившиеся канонизированные, конвенциональные типы идентитета, интеракции, институтов и создают повседневную социальную реальность, и при изучении интеракции их нельзя не принимать во внимание, напротив, именно они и заслуживают внимания. Институт - совокупность дискурсивных действий индивидов с определенными ролями-идентитетами, активирующимися в определенных ситуациях. Контекст определяет наиболее доминантный активирующийся аспект идентитета. Идентитет - активированная ситуацией модель поведения, дискурсовый носитель и выразитель этого поведения, в котором создается и отображается как феномен института, так и феномен идентитета. Однако, будучи конвенциональными явлениями, институт и идентитет влияют на использованный дискурс и в какой-то мере ограничивает его (JENKINS 2008: 339).

Нарратив обладает решающей ролью в процессе формирования идентитета. Идентитет в понимании М. Бамберга дуален: включает наличие некоторого постоянства и постоянного изменения. Эта динамика определяется 
потенциалом персоны, культуры или общества. Селф, личность проходит через процесс личного выбора и формативных или трансформативных событий. Возможность выбора, однако, не произвольна, выбор индивида - не свободный выбор, основанный на рефлексии. Происходит процесс навигации, базирующийся на доступных посредством культуры символических средствах, которые в свою очередь постоянно преобразовываются в этом процессе (BAMBERG 2011).

Другая двойственность - это конструирование деятеля самим собой, внутренними мотивациями и внешнее влияние, мир, образующий персону (другое направление влияния). Противоречие снимается, если рассматривать дихотомию внутреннего и внешнего как континуум с внутренним восприятием на одном его полюсе и влиянием извне на другом. Движение между двумя полюсами - динамичный процесс, распределенное во времени и пространстве, контекстуально и локально связанное явление (BAMBERG 2011).

Идентитет может быть описан в терминах позиции, отношений, членства, которые помогают нам проследить нарраторские средства, показать, как создаются идентитет, социальные отношения, социальные институты и как активные, принимающие участие в интеракции индивиды подвергаются контролю внешнего влияния, определяемого широким социально-культурным контекстом.

\section{2. Теоретические предпосылки и методика}

В дальнейшем параллельно друг с другом будут рассмотрены основные положения конверсационного и нарративного анализа (в дальнейшем - КА и НА) как методов работы с текстами.

Общая теоретическая цель упомянутого лингвистического метода - систематический анализ речи в интеракции «описание социальных практик $u$ ожиданий, на основе которых собеседники конструируют свое собственное поведение и интерпретируют поведение другого» (ИсуповА 2002: 36). Объектом исследования КА является разговорная речь, структура речи в интеракции. Речь строится из рядов, члены которых связаны причинно-следственными отношениями. Участники интеракции демонстрируют в своих рядах интерпретацию прозвучавших ранее предыдущих шагов, исследователь имеет возможность эксплицировать эти толкования в процессе лингвистического анализа (см. также HuTchBY-Wooffiтт 1998: 15). Основой же для взаимного понимания конверсации является членство - принадлежность к языковой группе, общине (о механизме категоризации членства подробнее см. SACKS 1992, IVÁNYI et al. 2002, IVÁNYI et al. 2003). На интерпретации прозвучавшего ранее строится самый надежный верификационный механизм КА: подтверждающая сила последующего ряда (НuTchBY-WoOfFITт 1998: 15).

Считающийся одним из основоположников НА, М. М. Бахтин выражал схожие с точкой зрения КА взгляды. Бахтин осмысляет понятие высказывания. Рассуждая о схематичном изображении коммуникации, он называет эти 
схемы научной фикцией, так как речь всегда носит активный, динамичный характер. Каждое высказывание - это звено в сложно организованной цепи других высказываний. Речевые жанры по Бахтину организуют нашу речь, как и грамматические формы. Мы предвидим, как будет развиваться ход диалога, и планируем его развитие соответственно нашим намерениям. Чем лучше мы владеем жанрами, тем проще нам выразить свою индивидуальность (БАхтин 1996).

Правоту бахтинских рассуждений подтверждают исследования КА - говорящий своими интерпретациями предыдущих речевых шагов задает соответствующую его коммуникативным целям траекторию речевой секвенции, ${ }^{2}$ своеобразный маршрут или план, который определяет предпочитаемые продолжения. Исходя из этого, Х. Сакс приходит к выводу, что повседневная конверсация в высокой степени упорядоченное, структурированное явление (there is order at all points) (Нuтснву-Woоfғтт 1998: 18-19, 22). Речь в интеракции, следовательно, упорядочена и структурирована, а задача исследования конверсационалистов - экспликация этой структуры.

Пытаясь осмыслить свою и чужую жизнь, люди оформляют свой опыт в форме нарратива (СHIARNAWSKA 2004: 5). Анализ нарратива рассматривает сам текст, который является осмыслением индивидуального и коллективного опыта, появляющегося в тексте. Это «режим» человеческого знания, наполняющего значением окружающий индивида мир. Нарратив фундаментален для восприятия. Нарративное исследование подразумевает реконструкцию личного опыта в отношении индивида к другим индивидам и социальной среде (PINNEGAR-DYNES 2007: 7). HA может расцениваться как интерпретативная парадигма, смысл текста которой структурирован контекстом, предмет исследования - это история, повествование, в котором появляются опыт индивидов и формы рассуждения о нем. Это способ конструирования смысла, реальности. Нарратив, таким образом, является социальной практикой (ПузАновА-ТРОцУк 2003: 64).

В этом НА очень близок к восприятию КА, рассматривающего язык в его социальных, межличностных, интерактивных проявлениях, вернее то, как сама социальная среда, институты, ритуалы, конвенции зарождаются и воссоздаются в процессе речевой деятельности (GoODWIN 1979, ScHEGLOFF 1980, Sacks 1984: 26, Psathas 1993, Русакова 2006). ${ }^{3}$

Нарративное исследование - квалитативный натуралистичный подход к объекту, он формируется вокруг интерпретаций индивидуального действия. Квалитативное исследование заинтересовано не в предсказании и контроле,

2 Это определяется О. Г. Исуповой как явление секвенционной импликативности: «высказывание одного из участников задает проект релевантного последующего действия, или нескольких действий, которые должны быть осуществлены следующим по очереди участником» (ИСУПОВА 2002: 42).

${ }^{3}$ Не случайно лингвисты употребляют выражения, связанные именно с речью как деятельностью, например: «a speaker's work on discourse production» (GÜLICH-KoTSCHI 1995: 30$31)$. 
а в понимании явления (PINNEGAR-DAYNES 2007: 4). КА также можно определить и как квалитативный натуралистичный метод: это связано с желанием $\mathrm{X}$. Сакса «поднять» социологию на уровень естественных наук. Для достижения большей объективности Х. Сакс исключает из умозаключительного процесса как «мешающие» факторы различные теоретические призмы (материал исследуется без предварительных теоретических рассуждений) и вводит требование основывать выводы только на эмпирическом материале (HuTCHBYWoOFFITT 1998: 24).

\section{3. Метод работы}

Метод и теория в работе X. Сакса трудно отделимы друг от друга, так как при описании повседневной социальной практики говорящих исследователь избегает применения предварительных гипотез и теорий, таким образом, языком описания может быть повседневный язык. Терминология КА детерминирована повседневной деятельностью говорящих (начало, конец секвенции, передача шага и т. д.) (Psathas 1993, Pomerantz 1984). Конверсационисты, в отличие от «традиционных» лингвистов, считали своей целью представить внутреннюю структуру процесса интеракции. Поэтому они опираются на эмпирический материал, магнитофонные записи.

КА - систематичный анализ ограниченной требованиями контекста интеракции. Выводы КА основываются на аудиозаписи разговора, записанного в естественных условиях и изготовленной по этому материалу транскрипции, и следуют из методичного описания и интерпретации транскрибированного материала. Транскрипция - не только способ представления языкового материала в КА, она порождает, наглядно демонстрирует и верифицирует выводы исследования. Таким образом, транскрибированный материал имеет для исследователей-конверсационистов определяющее значение.

Соавторы А. Роган и Д. де Кок указывают на трудности исследователя, желающего систематизировать разнообразные методы НА. Они говорят скорее о таксономии методов и предлагают делить их на три группы - перформативные методы, структурный анализ, анализ образного использования языка. Соавторы делят ход исследования на функциональную и аналитическую фазы. Функциональная область включает в себя инпут, выбор материала и конкретные действия с языковым материалом, а аналитическая часть анализа содержит саму интерпретацию нарратива, применения методов и их влияние. А. Роган и Д. де Кок рассматривают перформативные, структурные и образные методы анализа. В перформативной группе функциональная область включает в себя такие действия исследователя, как проведение интервью, подготовление секвенции вопросов, выслушивание, выделение значительных эпизодов. В группе методов структурного анализа производится анализ всего текста, содержания и дискурса, выбора языковых средств. На аналитическом уровне структурного анализа происходит рассмотрение зависимой от содержания интерпретации глобального значения текста, сбор элементарных, 
само собой разумеющихся деталей интерпретации глобального значения, возникновение значения в языке (RoGAN-DE KocK 2005: 637).

\section{4. Анализ текстов}

Чтобы проиллюстрировать изложенное ранее, привожу пример анализа отрывка из текста структурированного фокусированного группового квалитативного интервью беседы круглого стола по аптечной теме (ШАХвЕРдовА 2016). Участники собраны для исследования рынка, носящего социологический характер. Исследование проведено в одной из стран Прибалтики, все данные, указывающие на конкретные местные условия (названия улиц, вкрапления на языке страны) удалены. Ведущая - социолог, участники - рядовые граждане, мужчины и женщины, потребители в возрасте 50-70 лет, ближе к пенсионному возрасту, или уже на пенсии. Участники обозначаются цифрами, 1 - ведущая. Было обработано около 5 часов такой видеозаписи, рассматривались нарративы, связанные с формированием идентитета рядового потребителя, пожилого пациента, образа врачебно-фармакологической сферы. В данной статье этот анализ дополняется обзором структуры интеракции.

Ранее было произведено рассмотрение тем, выделение историй, анализ языковых средств, что являлось подготовительным этапом исследования, а интерпретация создания образа представителя услуг и потребителя - аналитическим (ШАХвЕРдовА 2016). Медицинская сфера фигурирует как враждебная среда в отношениях индивида и представителя медицинской сферы доминируют трудности коммуникации, особенно с врачом. Трудностями могут быть и языковой барьер, либо непонимание из-за разных профессиональных предпосылок и решение этих проблем потребителями-пациентами.

Нами были выделены те части текста, в которых упоминались врачи, в связи с ней можно было выделить следующие темы:

1) врач - к нему трудно попасть;

2) языковой барьер - не говорит по-русски;

3) барьер в понимании, говорит на профессиональном жаргоне, не понимает вопросов пациента;

4) относится к пациенту безразлично;

5) не дает достаточно информации;

6) «подвязан» к аптеке;

7) берет деньги, не предоставляя услуги или предоставляя услуги лишь для видимости (стоматолог);

8) выписывает рецепты «веером»;

9) партнер для разговора при интересе со стороны пациента.

Рассмотрим микроанализ отрезка текста, в которых появляется нарратив опыта взаимодействия пациента и медицинской сферы. Из-за ограниченного объема данной статьи мной рассматривается лишь один отрезок, в котором участники докладывают о своем негативном опыте в связи с медицинской 
сферой. Данная здесь транскрипция текста изготовлена в традициях КА, список условных обозначений см. в Приложении. Нарративный анализ не требует особой транскрипции.

6 Семейный врач (-); Вот у меня кончится лекарство от давления- (.) да, (.) выписывает, (-) я ей говорю, «я плохо себя чувствую больничные мне выпишите», (-) «не надо», она не выпишет (-) даже если я там эээхх загибаюсь, (.) у меня такой врач семейный; может мне это сейчас не надо; (.) может я сейчас не часто на больничных сижу мне это не надо, (-) просто отношение чисто наплевательское;=

1 =Ээ а кому вы больше доверяете; ээ (-) написанному слову, (.) провизору в аптеке или своему врачу; (-)

6 Конечно скорее написанному слову,=

3 =Конечно;

6 Ну теперь уже написанному слову; (-) и своему опыту; к сожалению;

9 Лучше же не проверяете,

6 Ну и плюс собственному опыту; (-) да; [...]

6 У нас всего два врача там сидит; (-) я поменяла шило на мыло; вторая очень занята, (.) но ее просто отношение, (.) заходишь, а она, «как вы себя чуувствуете, (.) а как у вас дела,(.) а на работе как,»

1 Ухм

6 Может ей до лампы моя работа и моя семья; (-) но просто- (-) а эта сидит, (.) симпатичная, молодая, миловидная все; но ей до лампы как я и что;

9 Вы к врачу пришли [или поговорить,]

6 [Я и с коробкой кон]феет могу прийти, это не меняет ее отношения ко мне, (.) нет это (???), она просто так по кругу;

1 Хорошо;

Приведенная история звучит в связи с темой «откуда пациенты берут информацию о лекарственных препаратах». Ранее говорящая 3 рассказывала о своем опыте, когда врач не давал ей достаточно информации касательно курса лечения, и ей пришлось осведомляться и выбрать курс лечения самой. Говорящая 9 выражает отличное мнение, говоря, что надо доверять врачуспециалисту. В приведенном отрывке говорящая 6 говорит о своем недоверии к врачам из-за их безразличия, приводя историю-пример.

Рассмотрим этот отрезок с точки зрения нарратива, а затем принимая во внимание и структурные особенности проходящей интеракции.

Говорящая не использует вводных выражений, указывающих на то, что последует история, для того чтобы обрисовать ситуацию, она говорит лишь семейный врач, что вызывает в сознании слушающих развертывающуюся ситуацию приема у семейного врача. У больной кончилось лекарство от давления и она очень плохо себя чувствовала. Врач на ее просьбу выписать ее на больничный лист отвечает лаконичным отказом. Несмотря на сильные страдания пациента (при описании своего состояния она использует интенсификатор даже, звукоподражание, изображающее хрип эээхх, экспрессивно 
окрашенную лексику загибаюсь), врач оценивает ее состояние как работоспособное, не требующее домашнего покоя. Врач не верит словам пациентки о ее физическом состоянии, а исходит из своих, непонятных пациенту, соображений. Говорящая 6 начинает оценку врача, но прерывает ее на дополнение, прояснение. Ей не всегда важно, чтобы был больничный лист, но она ощущает равнодушие со стороны врача. Затем следует оценка, подытоживая и оканчивая повествование - отношение чисто наплевательское.

Пациент оформляет свой рассказ в форме настоящего времени, которое придает ему обобщающее значение, у слушающего создается впечатление, что ситуация повторялась не один раз. Усиливает этот эффект употребление глагола СВ кончится: Вот у меня кончится лекарство от давления (можно понимать как: когда кончается, тогда я и иду к врачу). Следующий небольшой отрезок показывает, как изменилось мнение группы по отношению к доминирующему нарративу (в текстах интервью, наравне с недоверием пациента к медицинской сфере, часто реализуется нарратив: надо доверять авторитету врача, лицу с идентитетом специалиста) в ходе аргументации.

Далее говорящая 6 рассказывает о том, как она поменяла семейного врача, но остается недовольной и своим новым врачом - поменяла шило на мыло. Эта пословица означает 'поменять плохое на такое же плохое или даже худшее'. Пациентка рассказывает о причине смены врача: ее врач был очень занят (к нему трудно было попасть? надо было стоять в очереди? - тут слушатели не получают подробной информации), но врач всегда интересовалась ее делами, семьей, работой. При цитировании слов врача интонация говорящей становится более интенсивной, она сообщает об интересе и вовлеченности врача в жизнь пациента. Следует оценка - даже если такое поведение врача неискренне, это все равно приятно Может ей до лампь моя работа и моя семья, но просто. Конструкция опять эллиптическая, но нет сомнений в позитивной оценке такого поведения. Описание нового врача следует противопоставительной конструкцией $A$ эта сидит, симпатичная, молодая, миловидная, но ей до лампы все. Оценка поведения нового врача прерывается описанием внешности и новой противопоставительной конструкцией: несмотря на приятную внешность ей полностью безразлично состояние пациента, употребляется метафорическое выражение ей до лампь все. Реплика 9-й участницы свидетельствует о том, что по ее мнению в задачи врача не входит разговор с пациентом, но рассказчица оставляет это без внимания.

Раскроем более подробно структуру проходящей интеракции и ее влияние на интерпретации. После обозначения темы, которой говорящая 6 связывает свой рассказ с предпосылками, она начинает обрисовывать ситуацию, от общего наброска темы Семейный врач [...] кончится лекарство она переходит к описанию конкретного случая, используя дискурсивный маркер да, присоединяет отрезок. После более протяженной паузы рассказчица 6 приводит свой диалог с врачом прямой речью, с имитирующей интонацией, причем ударением выделяются слова загибаюсь / такой / семейный, выражая этим неодобрительную оценку в адрес врача, которому все равно, насколько 
плохо себя чувствует пациент. И даже если дела не так плохи, - акцент на словах не надо / не часто / не надо - все равно это противоречит ожиданиям пациента в отношении своего врача: больше внимания и эмпатии, а не «наплевательское отношение» - это выражение тоже выделяется в речи более интенсивным ударением. Модератор интервью задает вопрос в месте возможного взятия шага. Интонация тут опускающаяся, смысловое единство закончено, последняя часть высказывания является итоговой. Ведущая 1 берет слово без перерыва ни на долю секунды, в начале высказывания эканьем выигрывает время, чтобы подготовить свой вопрос, возвращаясь в русло беседы - от жалобы на безразличие врача - имплицитно выраженного недоверия к врачу - к тому, откуда информация, кому больше доверяют, работникам медицинской сферы или другим источникам. Своим ответом Конечно скорее написанному слову говорящая 6 выражает свое недоверие к врачам, хотя с долей неуверенности, выражающейся наречием скорее. 3-я говорящая вступает без перерыва, выражая то, что и она придерживается того же мнения. Неудивительно, так как ранее именно она ввела эту тему для обсуждения - врачи не заслуживают доверия. В следующей реплике 6 сообщает, что под влиянием разговора, и в свете упомянутых событий она тоже доверяет скорее другим источникам, Ну теперь уже написанному слову, что выделяется ударением, добавляется также и оценка: к сожалению, повтор фразы завершает эту секвенцию. Затем несколько реплик опускаются, речь звучит неразборчиво, симультанные отрезки некоторых говорящих накладываются друг на друга - происходит внутренний выбор / самовыбор говорящего. 6 решает продолжить начатую ею тему и дополнить ее новым примером. Она сравнивает двух семейных врачей их округа, причем вместо «два врача работают» употребляет выражение сидиm с выделяющим ударением. Слово «сидит» вместо «работает» носит некоторый негативный оттенок. После короткой паузы говорящая начинает новое тематическое единство - смена врача, но разницы с предыдущим нет - она все также недовольна врачом. Используется противопоставительная конструкция: одна из врачей всегда интересовалась ее состоянием, слова врача снова приводятся прямой речью с цитирующей интонацией, с особым выделением ударения и протянутостью гласного звука чуувствуете. А второму же врачу все равно. Хоть добавляется и оговорка Может ей до лампы моя работа и моя семья - все равно врач должен проявить интерес к пациенту. Говорящая 9 добавляет реплику в месте возможной смены говорящего с налагающимся отрезком $\mathrm{Bbl} \kappa$ врачу пришли [или поговорить,] - в обязанности врача это не входит по ее мнению, однако ее реплика игнорируется как и говорящей, так и остальными участниками разговора. Ведущая дискурсивным маркером с опускающейся интонацией завершает секвенцию.

Микроанализ отрывка текста интервью показал, что НА и КА взаимно дополняют и углубляют обработку текста, представляя возможность для описания поведения индивида в интеракции и проявления его идентитета. 


\section{5. Итоги}

Целью исследования ставилось проследить создание идентитета пациента, которое обрисовывается в речевом оформлении опыта пациента в сфере медицинских учреждений. После изложения теоретических и методологических предпосылок был представлен микроанализ отрывка, прозвучавшего в дискурсе фокусированного группового квалитативного интервью, связанного с аптечной темой. Основа наших теоретических предпосылок это то, что индивиды организуют свой жизненный опыт в форме нарратива, который представляет возможность для рассмотрения и осмысления различных социальных ролей и самого себя. Все это проявляется и в структуре конверсации, поэтому теоретическая и методологическая рамки - КА и НА. Было бы интересно дополнить анализ разговора больных о своем опыте в медицинской сфере анализом текстов, в которых происходит интеракция больнойврач, и такого же круглого стола для врачей.

В приведенном анализе, хоть и появляется идентитет пациента, доверяющего медицинской среде, опирающегося в своей аргументации на доминантный нарратив, согласно которому система требует безоговорочного доверия своим представителям, однако обрисовывается образ медицинской сферы как враждебной в отношении к пациенту среды, представитель которой, врач, недостоин доверия пациента. Врач не уделяет достаточно внимания из-за отсутствия времени или просто нежелания отвечать на вопрос, безразличия к пациенту.

Пациент появляется как непонимающий мотивы и соображения врача, осуждающий его безразличие. Пациент беспомощен, предоставлен часто самому себе, он переживает по этому поводу, но его действия (смена семейного врача) не приносят желаемых результатов. Таким образом наблюдается «спор» двух нарративов и создающихся на этой базе двух идентитетов пациента. Мы видим, что при помощи приведенного микроанализа нарратива возможно рассмотрение создания образа врача и идентитета пациента.

\section{Литература}

ANTAKI-WIdDICOMBE $1998=$ ANTAKI Ch., WidDICOMBE S. Identity as an Achievement and as a Tool. In: ANTAKi Ch., WidDicombe S. (ed.) Identities in Talk. London: Sage, 1998. $1-15$.

BAMBERG $2011=$ BAMBERG M. Who am I? Narration and its contribution to self and identity. Theory \& Psychology 21 (2011): 3-24.

ChIARNIAWSKA $2004=$ ChIARNIAWSKA B. The 'Narrative Turn' in Social Science Research. In: Chiarniawska B. Narratives in Social Science Research. London: Sage Publications, 2004. 1-16.

GoodwIN $1979=$ GoodwIN Ch. The Interactive Construction of a Sentence in Natural Conversation. In: Psathas G. (ed.) Everyday Language. Studies in Ethnomethodology. New York: Irvington, 1979. 97-121. 
Gülich-Kotschi 1995 = Gülich E., Kotschi T. Discourse Production in Oral Communication (A study based on French). In: Quasthoff U. M. (ed.) Aspects of Oral Communication. Berlin-New York: de Gruyter, 30-66.

Hutchby-Wooffitt 1998 = Hutchby I., Wooffitt R. Conversation Analysis. Principles, Practices and Applications. Cambridge: Polity Press, 1998.

IVÁNYI et al. 2002 = IVÁNYI Zsuzsanna, KERTÉSZ András, MARINECZ Kornélia, MÁTÉ Nóra: A társadalmi kategorizálás nyelvi eszközei a „Grüne Gentechnik” c. korpuszban. In: ANDOr József et al. (szerk.) Szöveg az egész világ. Petöfi S. János 70. születésnapjára. Budapest: Tinta, 2002. 269-292.

IVÁNYI et al. 2003 = IVÁNYi Zsuzsanna, KERTÉSZ András, MARINECZ Kornélia, MÁTÉ Nóra: A társadalmi kategorizálás grammatikája és pragmatikája. Modern Filológiai Közlemények 2003/1: 5-24.

JENKINS 2008 = JENKINS R. Social Identity. London-New York: Routledge, 2008.

Pinnegar-Daynes 2007 = Pinnegar S., Daynes J. G. Locating narrative inquiry historically: Thematics in the turn to narrative. In: Clandinin D. J. (ed.) Handbook of Narrative Inquiry. Mapping a Methodology. Thousand Oaks, CA: Sage Publications, 2007. 3-35.

Pomerantz 1984 = Pomerantz Anita: Agreeing and disagreeing with assessments: some feature of preferred / dispreferred turn-shapes. In: AtKInSON J. M., HeRITAGE J. (ed.) Structures of Social Action. Studies in Conversation Analysis. Cambridge: Cambridge University Press, 1984. 79-112.

Psathas 1993 = Psathas G. Conversation Analysis. The Study of Talk-in-Interaction. Thousand Oaks, CA: Sage Publications, 1993.

Rogan-DE Kock 2005 = Rogan A., DE Kock D. Chronicles From the Classroom. Making Sense of the Methodology and Methods of Narrative Analysis. Qualitative Inquiry 11 (2005): 628-649.

Sacks 1984 = Sacks H. Methodological remarks. In: Atkinson J. M., Heritage J. (ed.) Structures of Social Action. Studies in Conversation Analysis. Cambridge: Cambridge University Press, 1984. 21-27.

SACKS 1992 = SACKS H. Lectures on Conversation. Oxford: Blackwell, 1992.

SCHEGloff 1980 = Schegloff E. Preliminaries to preliminaries: "Can I Ask You a Question?" Sociological Inquiry 1980/3-4: 104-152.

SPENCER-OATLEY 2007 = SPENCER-OATLEY H. Theories of identity and the analysis of face. Journal of Pragmatics 39 (2007): 639-656.

БАХТИН 1996 = БАХТИн М. М. Проблема речевых жанров. В кн.: БАХтин М. М. Собрание сочинений. Т. 5. Москва: «Русские словари», 1996. 159-206.

ИсуповА 2002 = ИсуповА О. Г. Конверсационный анализ: представление метода. Сочииология 4М. № 15. Москва, 2002. 33-52.

ПузАновА-ТрОцук 2003 = ПузАнОВА Ж. В., ТрОцУк И. В. Нарративный анализ: понятие или метафора. Социология 4М. № 17. Москва, 2003. 56-82.

РуСАКОВА 2006 = РуСАКОВА О. Ф. Основные разновидности современных теорий политического дискурса: опыт классификаций. Политэкс 2006/3: 191-212.

ШАХВЕРДОВА 2012 = ШАХВЕРДОВА В. Иерархия в дискурсе правосудия: власть и подчинение в речи профессионала и гражданина (на материалах юридического шоу «Чac cyдa»). Debrecen: DU Press, 2012.

ШАХВЕРДОВА 2016 = ШАХВЕРДОВА В. Нарративный анализ идентитета, сконструированного в дискурсе фокусированного группового квалитативного интервью. Slavica 45. Debrecen, 2016. 63-84. 
Приложение

Условные обозначения в транскрипџии

\begin{tabular}{|c|c|c|}
\hline $\begin{array}{c}\text { Элементы артикуля- } \\
\text { ционных признаков } \\
\text { звучащей речи и вре- } \\
\text { менной организации } \\
\text { речевых шагов }\end{array}$ & Описание признака & Условное обозначение \\
\hline \multirow[t]{3}{*}{ Паузы } & $\begin{array}{c}\text { Микропауза: } \\
\text { короче } 0,25 \text { сек }\end{array}$ & (.) \\
\hline & $\begin{array}{c}\text { Короткие паузы: } \\
0,25-1,5 \text { сек }\end{array}$ & $(-)(-)(-)$ \\
\hline & Продолжительные паузы & (2 сек) (3 сек) (4 сек) \\
\hline \multirow[t]{2}{*}{ Симультанная речь } & Начало & {[} \\
\hline & Конец & ] \\
\hline Смутность & $\begin{array}{c}\text { Длина отрезка } \\
\text { соответствует времени } \\
\text { произношения }\end{array}$ & $(? ? ?)$ \\
\hline «Эканье» & $\begin{array}{c}\text { Длина отрезка } \\
\text { соответствует времени } \\
\text { произношения }\end{array}$ & эЭЭ \\
\hline \multirow[t]{5}{*}{ Интонация } & $\begin{array}{c}\text { Поднимающаяся } \\
\text { на высокий тон }\end{array}$ & $!$ \\
\hline & $\begin{array}{c}\text { Поднимающаяся } \\
\text { на средний тон }\end{array}$ & , \\
\hline & Парящая, однотонная & - \\
\hline & $\begin{array}{l}\text { Опускающаяся } \\
\text { на средний тон }\end{array}$ & ; \\
\hline & $\begin{array}{c}\text { Опускающаяся } \\
\text { на низкий тон }\end{array}$ & . \\
\hline \multirow[t]{2}{*}{ Ударение } & Особо сильное & $\begin{array}{c}\text { в связи с чем }(-) \\
\text { с какими }\end{array}$ \\
\hline & Сильное & Угнал автомобиль \\
\hline $\begin{array}{c}\text { Протянутость } \\
\text { гласных }\end{array}$ & $\begin{array}{c}\text { Длина отрезка } \\
\text { соответствует времени } \\
\text { произношения }\end{array}$ & $\begin{array}{c}\text { фаары - (-) решетка } \\
\text { радиаатора }\end{array}$ \\
\hline \multirow[t]{2}{*}{ Цитирование } & Начало & $\ll$ \\
\hline & Конец & » \\
\hline
\end{tabular}

